\title{
VARIABILIDAD EN LOS MODOS ARQUITECTÓNICOS INCAICOS. UN CASO DE ESTUDIO EN EL VALLE DE YOCAVIL (NOROESTE ARGENTINO) ${ }^{1}$
}

\author{
VARIABILITY IN INKA ARCHITECTURAL MODES. A CASE STUDY \\ IN THE YOCAVIL VALLEY (NORTHWEST ARGENTINA)
}

\author{
Myriam N. Tarragó* y Luis R. González**
}

\begin{abstract}
La ocupación incaica en los Andes Meridionales revistió cualidades particulares de acuerdo a las condiciones sociopolíticas y productivas que imperaban en los territorios que eran integrados al Tawantinsuyu. El registro arquitectónico resulta un aspecto sensible para el estudio de las estrategias implementadas en cada caso y del grado de articulación de las sociedades locales con la administración estatal. Al respecto, en esta presentación analizamos y discutimos los rasgos de la construcción del espacio social asociados a la presencia imperial, a través de un caso bajo investigación, el del asentamiento Ampajango 2-Rosendo Cáceres, ubicado en el sur del valle de Yocavil, provincia de Catamarca.
\end{abstract}

Palabras claves: ocupación incaica, Andes Meridionales, registro arquitectónico, valle de Yocavil.

The Inka occupation in the South Central Andes took on diverse specific characteristics, according to the prior social, political and productive conditions that dominated in territories being incorporated into Tawantinsuyu. The architectural record emerges as a feature useful for study of the strategies implemented in each case and the level of articulation of local societies with the Inka state administration. Here we analyze and discuss features of the construction of social space associated with the imperial presence, in a case under investigation in Ampajango 2-Rosendo Cáceres, a complex and rich site in the southern part of the Yocavil Valley (Catamarca-Argentina).

Key words: Inka occupation, Southern Andes, architectural record, Yocavil Valley.

El sector meridional del valle de Yocavil, en la provincia de Catamarca, constituyó uno de los paisajes más densamente poblados del Noroeste argentino durante los momentos prehispánicos tardíos. Los asentamientos, de distinta envergadura, se escalonan con regularidad siguiendo el eje norte-sur del valle, poniendo de manifiesto una alta tasa demográfica que debió sostenerse con prácticas intensivas de producción de alimentos. La información arqueológica da cuenta de un proceso de paulatino incremento en la escala de producción de bienes artesanales, siendo conocidos los casos de la alfarería y la metalurgia "santamarianas". Cuando la región fue activamente incorporada al Tawantinsuyu, los administradores cuzqueños encontraron una organización sociopolítica de una expansión territorial relativamente amplia, con estratificación interna en cuanto al acceso al poder y recursos y una articulación jerárquica de instalaciones de distinta magnitud y funciones. En tal sen- tido, el poblado de Rincón Chico (Tarragó 1987, 1998) parece haber ejercido una supremacía en el sistema de asentamiento que combinaba emplazamientos en el interior de las serranías y poblados erigidos junto a cursos de agua permanente, los que habrían alcanzado un importante papel como proveedores de alimentos para el centro político (González y Tarragó 2005; Nastri 1998; Tarragó y Nastri 1999).

En este trabajo presentamos un conjunto de datos surgidos de investigaciones que se encuentran en curso en el asentamiento Ampajango 2, Rosendo Cáceres. Este poblado, sobre el cual no se había presentado un informe detallado hasta este momento, evidencia una larga historia de desarrollo local y fue parcialmente ocupado y remodelado a partir de la dominación imperial en la región. Enfatizando algunas características del registro arquitectónico de uno de los sectores del asentamiento, proponemos un conjunto de hipótesis acerca del

\footnotetext{
* CONICET-Museo Etnográfico "Juan B. Ambrosetti” (F.F. y L - U.B.A.), Moreno 350 (1091), Buenos Aires, Argentina. mtarrago@mail.retina.ar

** Departamento de Ciencias Antropológicas (F.F. y L - U.B.A.), Moreno 350 (1091), Buenos Aires, Argentina.
} 
significado de las transformaciones del espacio impuestas por la administración incaica en el marco de la dinámica de dominación en el sur del valle de Yocavil.

\section{El Incario en el Sur del Valle de Yocavil: Espacio y Dominación}

La región que nos ocupa acreditó para la organización incaica un definido interés estratégico, considerando que el ramal troncal de la ruta que conectaba la provincia de Quire Quire con el corazón del imperio corría por el fondo del valle. Es presumible que también fuera importante desde el punto de vista económico, teniendo en cuenta su potencial productivo en alimentos y la existencia de talleres metalúrgicos atendidos por mano de obra habilidosa y entrenada. No obstante, las referencias tradicionalmente consignadas acerca de la presencia estatal en nuestro sector de estudio (Figura 1) fueron escasas y limitadas a dos instalaciones separadas por casi $50 \mathrm{~km}$, Fuerte Quemado y Punta de Balasto (Raffino 1981, 1988; Williams 1994; Williams y D'Altroy 1998). Recientemente hemos dado a conocer evidencias que cubren ese intervalo espacial, obtenidas a lo largo de diecisiete años de trabajos en la región y que ponen de manifiesto que la ocupación cuzqueña no siempre se ajustó a criterios "monumentales" (González Godoy 1996:34) y que el registro arqueológico imperial puede quedar empañado en contextos con preponderancia de elementos locales (Meyers 1999:244; Morris 1988:243-244). Sobre el particular, hemos propuesto que, en el sur del valle, la dominación incaica, sin dejar de ser intensa, implicó un complejo proceso en el que participaron los intereses del gobierno central y los de los grupos de poder locales, los mecanismos diseñados para alcanzar los objetivos del Estado y las cualidades de la organización social, política y económica vigente en la región y la resolución de los conflictos de facciones derivados de las nuevas condiciones (González y Tarragó 2005; Reynoso 2003). A partir de ello, sería esperable que el registro arqueológico imperial en la región, teniendo en cuenta las características organizativas preexistentes, exhibiera una amplia variabilidad, cuya evaluación requiere trascender las rígidas listas de indicadores estimados como "típicos".

Por otra parte, la eficacia en la aplicación de la política económica estatal no se basó únicamente en el despliegue de mecanismos coercitivos, sino también, y de modo fundamental, en la apropiación, reformulación y redimensionamiento del aparato ideológico local, orientándolo hacia los principios que apuntalaban la estructura y la legitimidad del Estado (Conrad 1992; Patterson 1992). Sobre el particular, la creación de nuevos sentidos en la concepción del espacio, como ámbito para la acción de los agentes sociales, parece haber constituido una de las herramientas preferidas empleada por los planificadores estatales (Moore 1996). De tal forma, el estudio del modo en que el espacio fue reestructurado puede proporcionar claves relevantes para asomarnos a la compleja articulación de la administración estatal con las comunidades locales.

Partimos de considerar que las soluciones arquitectónicas aplicadas en el pasado no surgieron sólo de consideraciones prácticas. Por el contrario, también respondieron a elecciones culturales, las que, en última instancia, remiten a los grandes principios ideológicos a partir de los cuales ciertos grupos de la sociedad se significaron a sí mismos y a su mundo dando categorías a su rol social y al de los otros (Cosgrove 1984:15). En consecuencia, la inserción en el paisaje y la forma en que tal inserción tuvo lugar no puede abordarse únicamente desde la óptica de un mero proceso evolutivo motorizado por requerimientos, tales como ajustes al ambiente, expansión demográfica o necesidades funcionales y condicionado por las características del terreno. Estimamos que las propuestas explicativas requieren evaluar la dialéctica entre la producción material, en este caso la producción arquitectónica, y las condiciones superestructurales que dictaminaron sobre el sentido de dicha producción (Tarragó y González 2004). La delimitación de un espacio cultural particular supone un proceso social de edificación de la realidad a partir de un determinado sistema de saber (Criado Boado 1993:11; Penning Roswell 1986:115; Tilley 1994:10), dentro del cual la naturaleza fue sometida a un proceso de domesticación. De tal modo, el entorno dejó de ser aleatorio para transformarse en predecible, ordenado y cargado de significación. La domesticación del paisaje puede verse como la expresión de una situación similar aplicada al grupo social: como en aquel caso, los hombres fueron ajustados a ciertas pautas que eran manipuladas por elites políticas históricamente contingentes (Tarragó y González 2004). En esta dinámica de creciente control social, la arquitectura asumió un rol acti- 
vo, separando a las elites de los comunes, restringiendo el movimiento hacia determinados sectores y transmitiendo, a través de cualidades constructivas, mensajes de diferenciación, poder y prestigio. Los espacios vinculados con las actividades ceremoniales y religiosas fueron, probablemente, los monumentos más versátiles para crear y reproducir las estructuras de poder social. Por un lado, conformaban lugares de convergencia en los cuales las condiciones de desigualdad podían enmascararse a partir de su apariencia pública. Por otro lado, los fundamentos del orden impuesto podían ser renovados y potenciados mediante la in- tervención de fuerzas sobrehumanas, las que, a su vez, eran presentadas como legitimadoras de la estructura de dominación vigente.

\section{Ampajango 2, Rosendo Cáceres}

El asentamiento cubre una superficie mínima de 11 há, a 2.100 msm y se ubica a $35 \mathrm{~km}$ al sudeste de la ciudad de Santa María y a $6 \mathrm{~km}$ al oriente de la ruta 40, que corre por el fondo del valle y cuya traza coincide aproximadamente con el antiguo camino troncal incaico (Figura 1). Se emplaza a lo largo de una angosta terraza que corre entre el

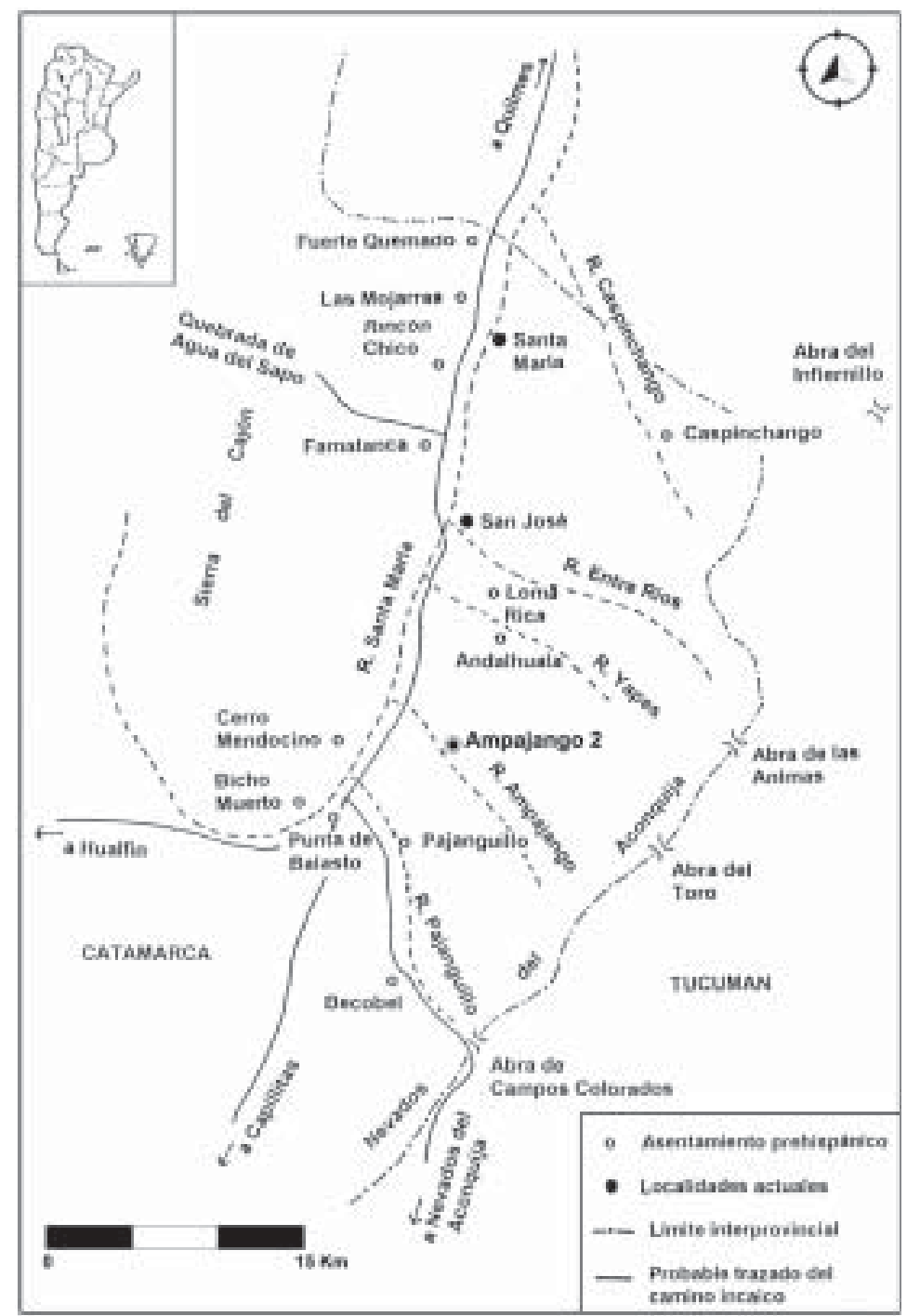

Figura 1. Esquema del valle y ubicación de Ampajango (tomado de González y Tarragó 2004). Map of the valley and location of Ampajango (after González and Tarragó 2004). 


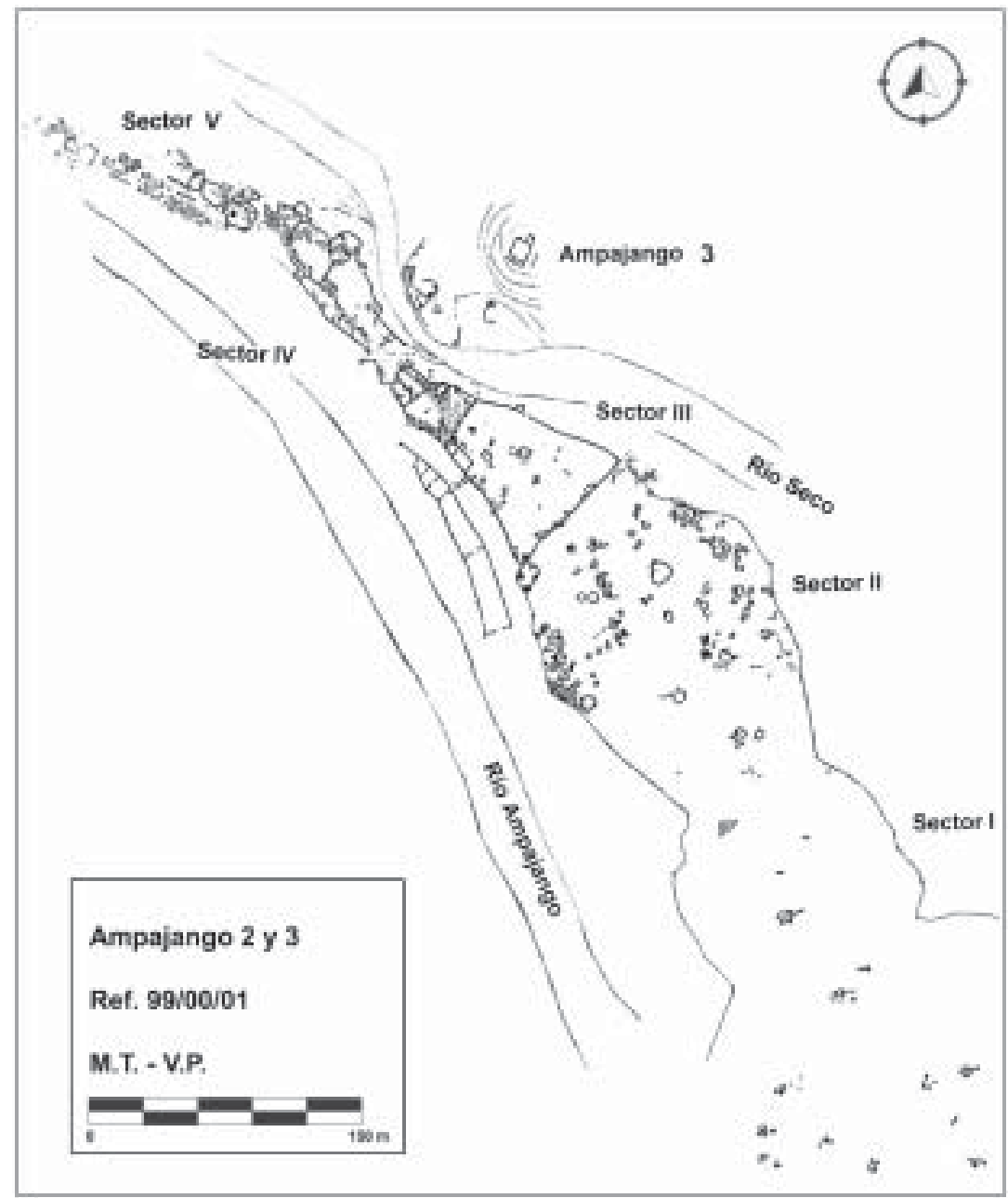

Figura 2. Distribución de sectores de Ampajango 2.

Distribution of sectors in Ampajango 2.

río Ampajango y un profundo cauce estacional. A comienzos de la década de 1960 un equipo de la Universidad de Rosario, en el que participó uno de nosotros (MNT), visitó el lugar. Si bien se efectuaron excavaciones en algunos recintos, no se publicaron detalles de los trabajos (Cigliano 1966; Lorandi 1966:52-53; Tarragó 1964). En 1991 se realizó una prospección expeditiva en la plaza del sitio, durante la cual fue recuperado en superficie un liwi de bronce estañifero de clara raigambre incaica (González y Palacios 1996). Investigaciones sistemáticas se iniciaron en 1999, que tenían como principales objetivos el relevamiento general del sitio, el registro planimétrico de estructuras y la recuperación de materiales para ensayar estimaciones cronológicas. De acuerdo a las evidencias arquitectónicas y al material cerámico de superficie, el sitio muestra una prolongada ocupación, por lo menos desde el período de Integración Regional.

El relevamiento permitió establecer delimitaciones de sectores a partir de muros que cortan transversalmente la terraza y que coinciden con desniveles en la pendiente del terreno (Figura 2). Circuitos de circulación planificados recorren el asentamiento, con rampas que permiten pasar de un sector a otro. Los sectores extremos, I y V, son los que se presentan en peores condiciones de conservación. El primero, ubicado en las cotas más altas, presenta vestigios de recintos aislados, circulares y rectangulares, parcialmente sepultados por la acumulación de derrubios y la vegetación arbustiva. Es posible 
que este sector corresponda a las ocupaciones más antiguas, anteriores al siglo X d.C. Los restos culturales en superficie son muy escasos.

Por su parte, en el sector II, se computaron más de 70 recintos, la mayoría de ellos de forma circular y cuyas dimensiones varían desde el metro hasta los $6 \mathrm{~m}$ de diámetro. Algunos de sus muros son con doble línea de piedras y otros de líneas simples. Si bien dentro del material de superficie hay diversidad en los tipos cerámicos, predominan los estilos tardíos, el Santamariano y el Negro sobre Rojo pulido incaico, además de utilitarios alisados. Otros materiales que se registraron sin ser recuperados son varias piedras de molienda. En el mismo sector se observaron numerosos fragmentos de mineral de cobre porfídico. Fue registrado un gran bloque pétreo in situ grabado con motivos figurativos y abstractos. Cabe consignar que a $2.5 \mathrm{~km}$ hacia el fondo del valle se encuentran los conocidos campos de petroglifos de Ampajango, donde se ha registrado este estilo (Lorandi 1966).

El sector V se encuentra en los terrenos más cercanos al fondo del valle, los cuales han sido muy alterados por ocupaciones modernas, agricultura y obras hidráulicas de importancia. En superficie abundan los fragmentos de alfarería, pero los muros de las construcciones prehispánicas han sido borrados casi en su totalidad. Líneas de piedras que acompañan el curso del río Ampajango sugieren la existencia de antiguas parcelas de cultivo que habrían cubierto una superficie de entre 10 y 15 há. En este sector falta completar el relevamiento planimétrico.

En los sectores III y IV, las construcciones cubren la totalidad de la superficie plana de la terraza, cuyos bordes fueron marcados con un extenso muro de circunvalación, el cual incluye aberturas para descender hacia los terrenos bajos de los costados. Además de alfarería, se recuperaron en superficie núcleos y lascas de reducción secundaria de andesita, basalto y, en menor medida, obsidiana y cuarzo. En el sector IV las estructuras fueron levantadas con pirca doble, utilizándose bloques irregulares y aprovechando, en ocasiones, peñascos in situ. Los recintos se presentan agrupados, con plantas de tendencia rectangular. Entre ellos se distribuyen estructuras circulares de pequeño diámetro, algunas de las cuales probablemente constituyeron depósitos. El espacio aparece organizado por una vía de circulación longitudinal que recorre el asentamiento y que, en ciertos lugares, alcanza un ancho de $3.5 \mathrm{~m}$ (Figuras 2 y 3 ). De ella se desprenden senderos secundarios que descienden hacia las quebradas laterales.

Sobre la terraza baja del río Ampajango se observan recintos de siembra rectangulares alar-

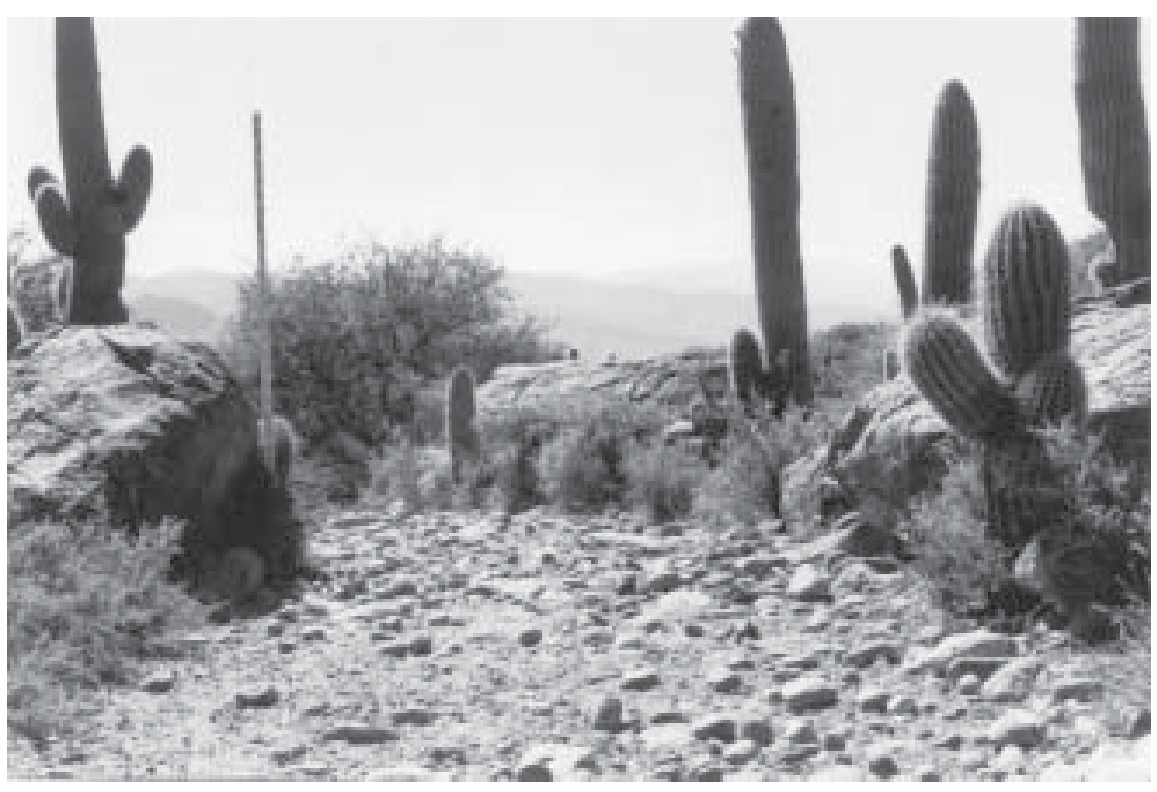

Figura 3. Vista del camino principal.

View of the main road. 


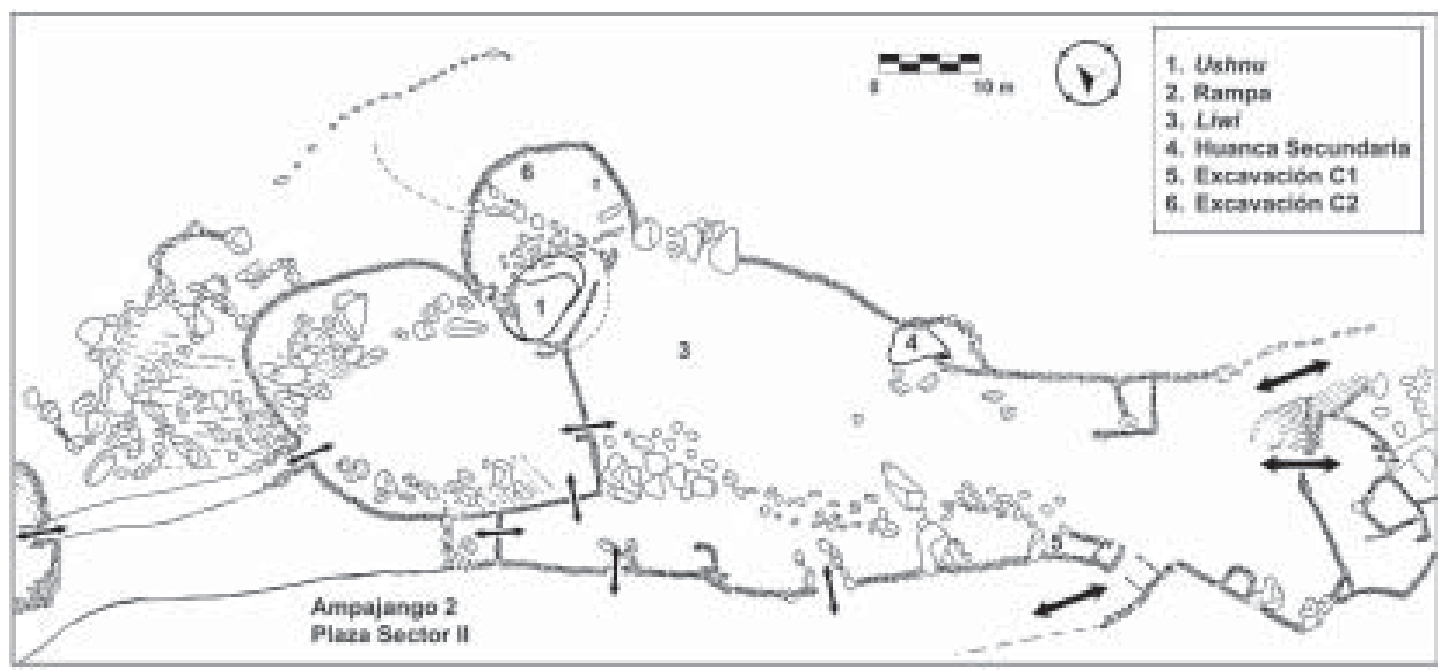

Figura 4. Plano del sector IV y la plaza (tomado de González y Tarragó 2004).

Plan of sector IV and the plaza (after González and Tarragó 2004).

gados que abarcan 1.5 há. Aguas arriba se detectaron al menos tres grupos de canchones similares. El desnivel de unos $10 \mathrm{~m}$ entre la playa y la superficie de la terraza, es vencido con dos rampas escaleradas de $2 \mathrm{~m}$ de ancho. La empinada ladera, además, fue reforzada con líneas de muros de contención construidos con piedras desbastadas. De igual modo, la playa del río parece haber constituido una "cantera", en donde grandes rodados de granito y andesita fueron utilizados para preparar bloques de construcción. Además de grandes lascas, fueron registradas piedras con marcas de barreno de sección triangular y poco profundo. En algunos muros de las construcciones sobre la terraza se detectaron bloques que aún conservaban las mismas marcas.

El área más prominente del sector incaico de Ampajango 2 es su plaza central, la cual, siguiendo la topografía, presenta una planta poligonal con una tendencia norte sur (Figura 4). En su extremo sureste, una rampa de $3.5 \mathrm{~m}$ de ancho, tras descender al cauce estacional, conduce al conjunto denominado Casas Viejas (Ampajango 3). En dirección contraria, una de las escaleras mencionadas previamente lleva a la playa del río Ampajango, donde comienzan los cuadros de cultivo (Figura 5). La plaza se encuentra demarcada por un muro de circunvalación de pirca doble, habiéndose aprovechado en algunos puntos la presencia de grandes bloques de derrubio. Sin embargo, el espacio interior se encuentra despejado, lo que sugiere que se implementaron intensos trabajos de despedrado de los

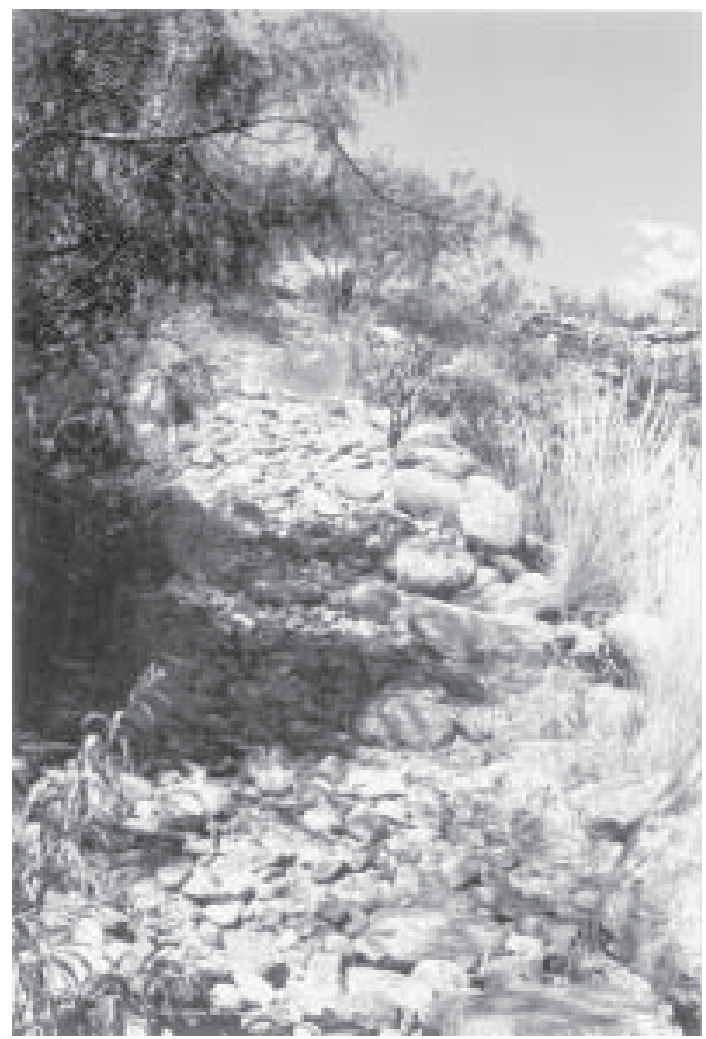

Figura 5. Escalera de ascenso desde el río Ampajango. Access stairway from the Ampajango river.

grandes cantos rodados que constituyen la estructura geológica de la terraza cuaternaria. En el borde occidental, a una cota levemente más baja que la de la superficie principal y separada de ésta por 


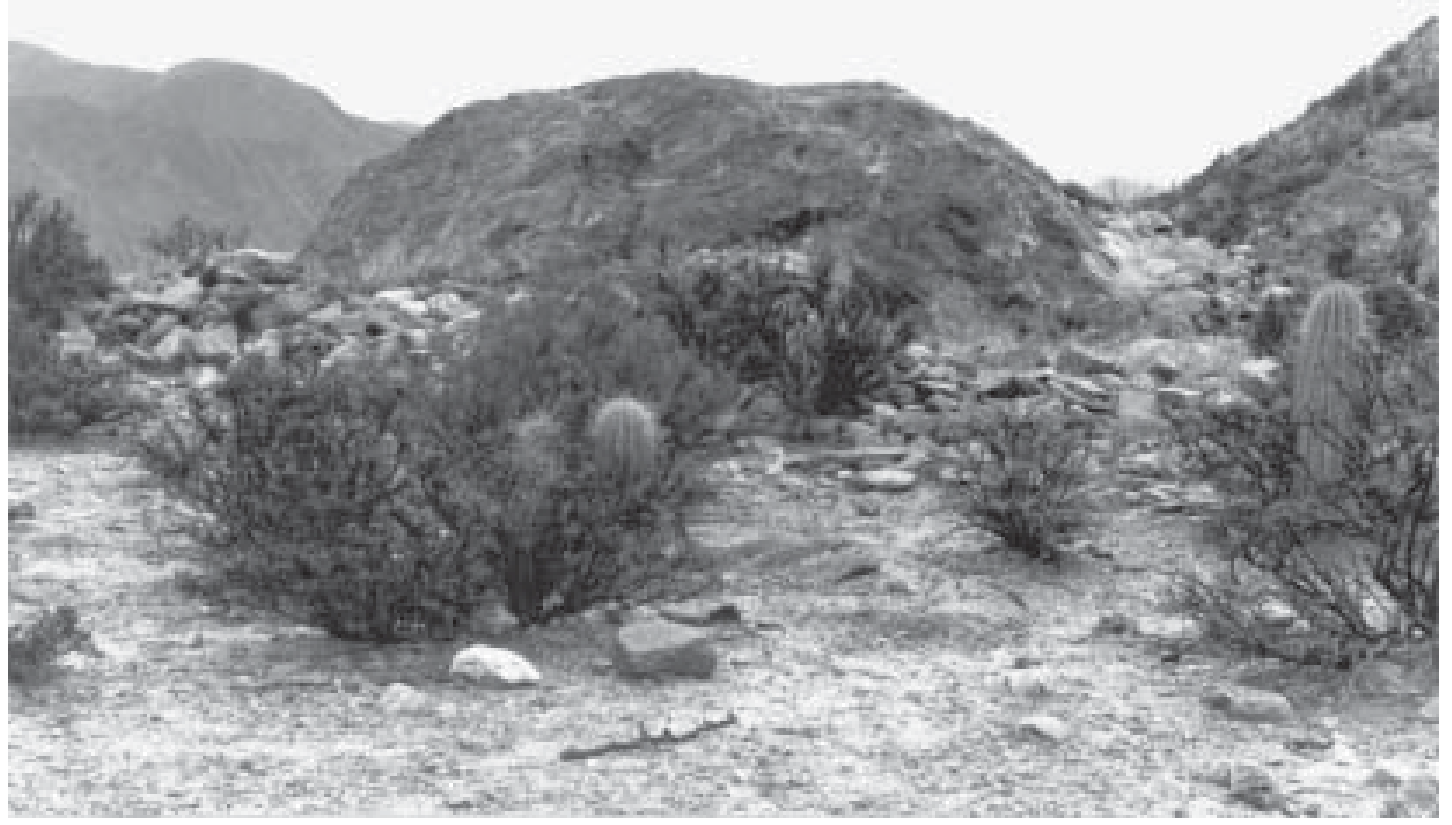

Figura 6. Vista desde la plaza de la gran roca - ushnu.

The great rock - ushnu - viewed from the plaza.

un alineamiento de grandes peñascos, se ubica media docena de recintos de tendencia rectangular. De igual modo, hacia el noroeste, se presenta un gran recinto de forma irregular, que también fue despedrado en su parte central y al que se accede por una estrecha puerta de un metro de ancho.

En la esquina norte de la plaza se encuentra una estructura dominada por un enorme peñasco de $10 \mathrm{~m}$ de largo en sentido este-oeste, $4 \mathrm{~m}$ de ancho en sentido norte-sur y $3 \mathrm{~m}$ de altura promedio (Figura 6). En su cara sur, que mira hacia la plaza y, más allá, hacia las cumbres nevadas de la cadena del Aconquija, el peñasco fue enmarcado con dos líneas de plataformas realizadas con rocas de formas regulares, algunas de ellas con canteado expeditivo. Hacia el norte y este, el desnivel del terreno fue compensado con cuatro y cinco líneas de plataformas, habiéndose incluido, además, una rampa que permite ascender a la cúspide plana de la gran roca (Figura 7). Más allá se presentan dos grupos de plataformas semicirculares que terminan en un muro en el borde de la terraza. Un segundo peñasco, rodeado de una plataforma y de menores dimensiones, se ubica en un costado de la plaza, al sudeste de la roca mayor. En el interior de la plataforma se registraron fragmentos de escorias de fundición de metales.

Fueron excavadas dos cuadrículas exploratorias que totalizaron ocho $\mathrm{m}^{2}$. En una de ellas, al sur de la plaza, la superficie de ocupación se ubicó a $30 \mathrm{~cm}$ de profundidad, debajo de las rocas de derrumbe. Un primer fechado sobre carbón vegetal proporcionó un valor correspondiente a $340 \pm$ 130 a.p. (Cal. 1 sigma, 1430-1660 d.C.; Cal 2 sigmas 1320-1950 d.C.; Beta-146374). En la otra cuadrícula (C2) abierta en la estructura anexa hacia el norte de la plaza (Figura 4) se registró una superficie de ocupación bien conservada y un área con sedimento termoalterado. Un hallazgo significativo lo constituyó un fragmento de una cadenita de hierro, correspondiente a momentos del contacto hispano-indígena; un análisis preliminar de la misma reveló que los eslabones fueron manufacturados por forja de pequeños alambres de grosor irregular (Figura 8).

La muestra cerámica de superficie y de excavación ofreció tipos Gris Pulido, Famabalasto Negro sobre Rojo, Santa María Bicolor, Belén Santa María, Quilmes Rojo Grabado e Inca, entre ellos Inca Paya y Cuzco Policromo. A poca distancia 


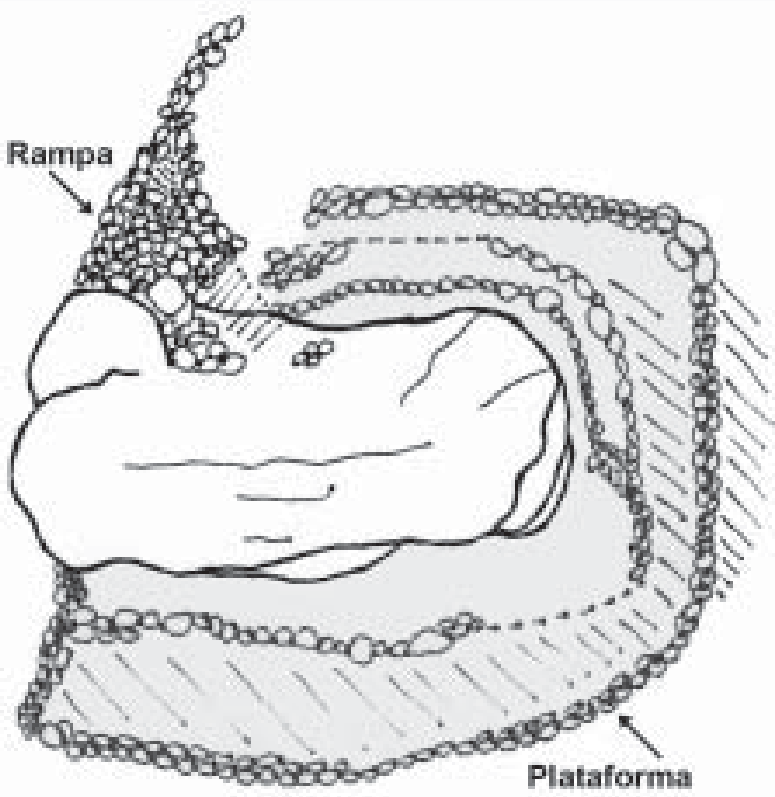

Figura 7. Planta del ushnu, esquina norte de la plaza.

Ushnu plan, North corner of the plaza.

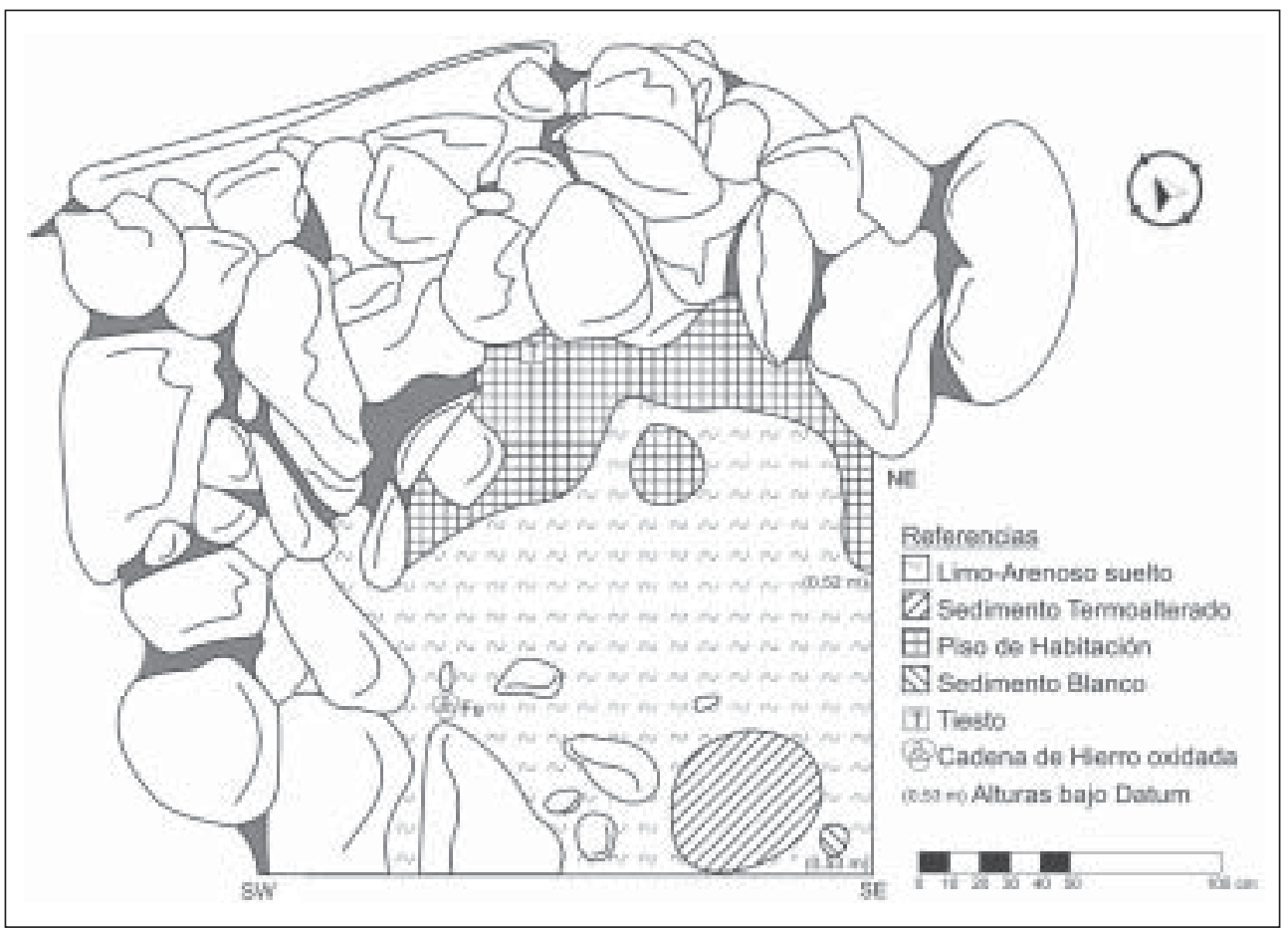

Figura 8. Planta de excavación, Cuadrícula 2.

Excavation plan, Square 2. 
de Ampajango 2 se encuentran otros conjuntos de construcciones, presumiblemente relacionados con el asentamiento mayor. Hacia el sur, del otro lado del río, fue registrado Ampajango 4, en donde se encuentran estructuras rectangulares y circulares con muros muy derrumbados, recuperándose en superficie fragmentos de alfarería de tipo incaico. Hacia el norte, a unos $100 \mathrm{~m}$ y tras cruzar el cauce estacional, se ubica Ampajango 3, Casas Viejas, caracterizado como un conjunto del tipo kancha, con cuatro cuartos de planta rectangular (Figuras 2 y 9). Los muros, que en algunos puntos conservan $1.5 \mathrm{~m}$ de altura, fueron levantados con doble hilera de pirca, con piedras sin trabajar pero seleccionadas por su geometría regular. Por su posición, sobre un promontorio en el borde de la quebrada del río Seco, este sitio constituye un excelente puesto de observación del asentamiento mayor. Al noroeste de Ampajango 3 se encuentra la Loma Redonda (Ampajango 7), una elevación de cima relativamente plana y a la que se asciende por el sureste. A distintas alturas sobre la ladera fueron ubicadas cuatro plataformas, realizadas con muros dobles con relleno y que acreditan buena conservación. La mayor de estas plataformas mide $6 \mathrm{~m}$ de largo por $3 \mathrm{~m}$ de ancho. A poca distancia hacia el oeste, en un quiebre de la pendiente, se registró una prominente apacheta cuyas características sugieren un uso subactual pero sobre una estructura muy antigua. La amplia cima de la loma (aproximadamente, 240 por $150 \mathrm{~m}$ ), se encuentra en gran parte delimitada por un muro perimetral, de pirca doble con relleno, al que se adosan algunos recintos rectangulares y circulares de pirca simple (Figura 10). Es posible que en el espacio interior existan otras estructuras, ocultas por la espesa vegetación arbustiva. Es de relevancia mencionar que desde la Loma Redonda, así como desde las plataformas en su ladera, se tiene un dominio visual completo de Ampajango 2 y del sur del valle de Yocavil, hasta la cadena del Aconquija y, por ende, del tránsito por el Camino Troncal Inca.

\section{Transformaciones}

El relevamiento del área edificada y el estudio de los materiales recuperados en superficie no de-

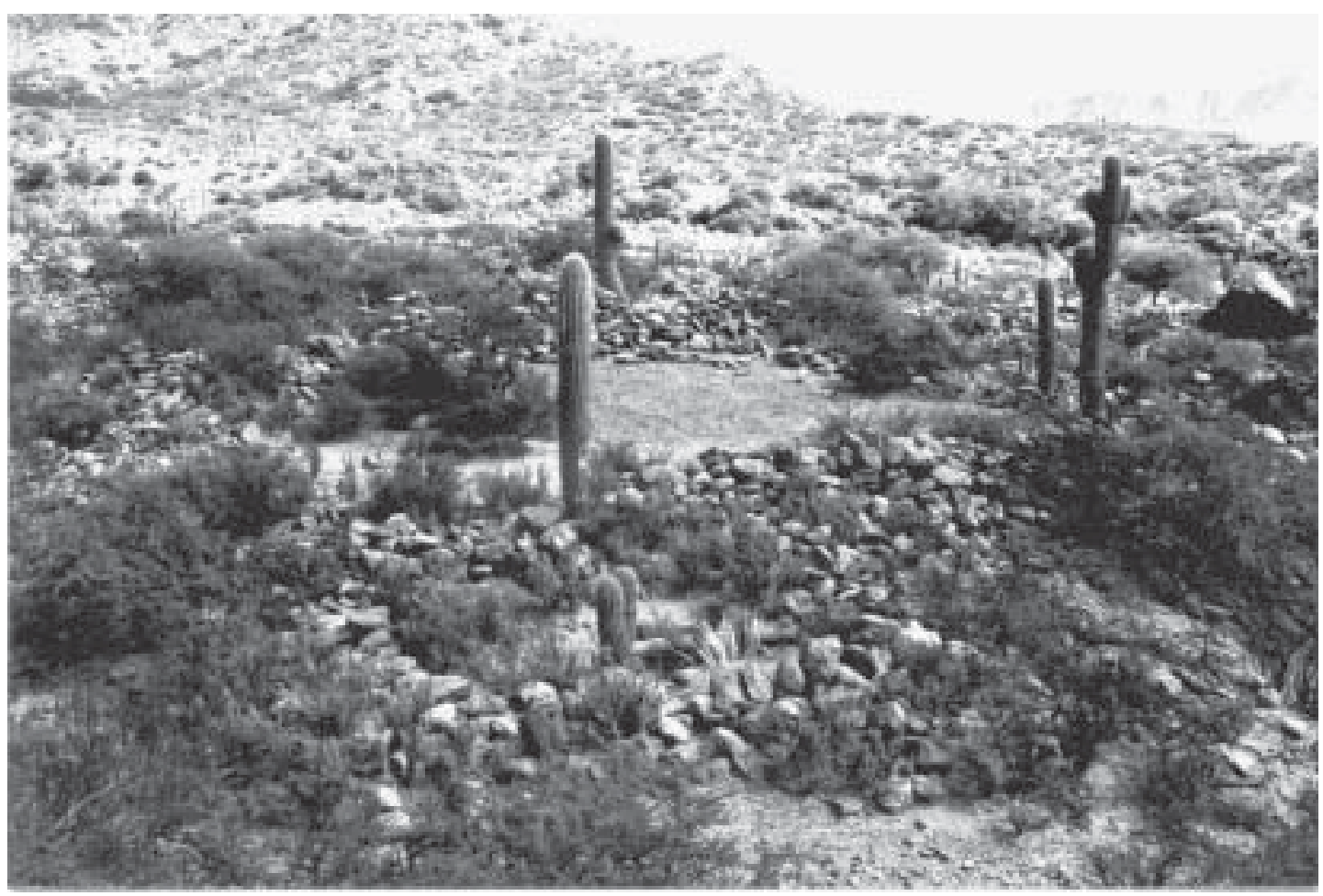

Figura 9. Vista de Casas Viejas, Ampajango 3.

View of Casas Viejas, Ampajango 3. 


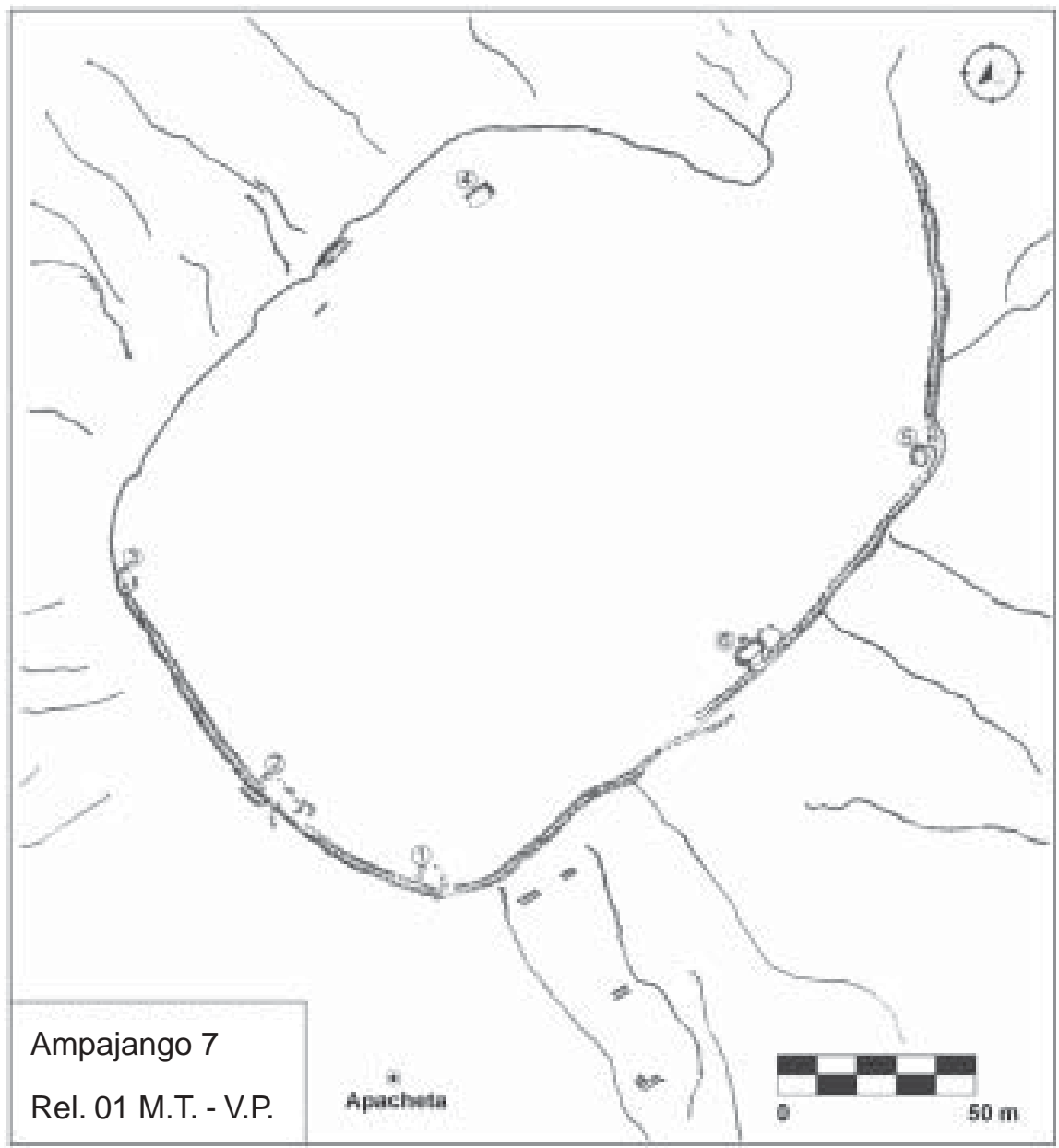

Figura 10. Plano de Loma Redonda, Ampajango 7.

Plan of Loma Redonda, Ampajango 7.

jan lugar a dudas que el asentamiento experimentó un prolongado desarrollo, a partir de momentos agropecuarios tempranos. Esta situación fue compartida por otros poblados de similar emplazamiento: a alturas medias y sobre ríos de aguas permanentes de la vertiente occidental de la cadena del Aconquija. Tal es el caso, por ejemplo, de la Banda de Andalhuala, Soria 2,2 km al norte, Caspinchango, $30 \mathrm{~km}$ al norte y Pajanguillo, $5 \mathrm{~km}$ al sur. Las excepcionales condiciones hídricas de estas zonas, considerando el ambiente árido a semiárido que domina el sur del valle, probablemente estimularon la paulatina intensificación de las actividades agrícolas y el crecimiento de los asentamientos. Como se dijera, se ha propuesto que, hacia los momentos preincaicos tardíos, estas áreas habrían pasado a formar parte de un sistema de complementariedad funcional, como proveedores de recursos alimenticios para núcleos políticos emplazados en el fondo del valle. Como en Ampajango 2, para Pajanguillo y Caspinchango existen registros de materiales incaicos (González y Tarragó 2005). La presencia imperial en estos poblados podría explicarse en el marco de objetivos de incrementar la producción agrícola zonal. Es presumible que la infraestructura de cultivos local haya sido redimensionada en un grado que aún estamos incapacitados de evaluar. De todos modos, no hay evidencias que sugieran la implantación de mitmaku$n a$. Las alfarerías habitualmente mencionadas como indicadores de la presencia de grupos foráneos, como Yocavil y Famabalasto Negro sobre Rojo, son elementos absolutamente minoritarios frente a los tipos locales como el Santamariano. Consideramos, en consecuencia, que la mano de obra local fue la 
encargada de continuar las actividades de producción de alimentos, aunque de acuerdo a una nueva organización.

Pudo resultar de importancia estratégica para la administración estatal que Ampajango 2 se encontraba a mitad de camino en un corredor natural que acompaña el cauce del río y que desemboca en pasos que atraviesan la cadena del Aconquija hacia la vertiente tucumana. Hasta no hace mucho, estos pasos eran aún utilizados por arrieros que trasladaban animales en época de invernada para aprovechar los pastos del lado oriental. Contamos con información confiable acerca de la existencia, entre los 3.000 y $3.500 \mathrm{~m}$, de ruinas de construcciones y tramos de antiguas calzadas. También se ha planteado que en los momentos previos a la llegada incaica, las unidades sociopolíticas de Yocavil habían instalado colonias productivas en lugares alejados hasta una jornada de marcha de las cabeceras, entre ellos en el fértil valle de Tafí (Tarragó 1999:479). A partir de ello, puede proponerse que los administradores imperiales se apropiaron de este circuito, no sólo para mantenerlo en operación sino también para controlar la frontera oriental del Collasuyu en la zona. En este sentido, estaríamos frente a una situación similar a la que se registra a pocos kilómetros al sur, con las instalaciones de Becobel, Tambo Colorado y Nevados del Aconquija, estas dos últimas emplazadas sobre el filo de la cadena montañosa y supervisando, entre otras funciones, las comunicaciones con las tierras bajas tucumanas (Hyslop 1990:79-82; Hyslop y Schobinger 1991).

En lo que es de interés para estas páginas, queremos resaltar que la ocupación incaica en el sector IV de Ampajango 2 parece haber implicado dramáticas remodelaciones arquitectónicas. Pero sus cualidades no se ajustan con toda definición a los rasgos considerados típicos para evaluar la presencia imperial en el noroeste, sino que resultaron de la aplicación, en lo fundamental, de las técnicas constructivas locales. La implantación del nuevo orden se tradujo en una resignificación del espacio, proceso en el cual unos pocos detalles de la refinada arquitectura imperial (por ejemplo, las piedras canteadas) llegaron a destacarse en un contexto dominado por el estilo constructivo local. Al respecto, resulta significativo reparar en los lugares del sector en los cuales los administradores cuzqueños decidieron invertir trabajo y cuidado constructivo.
Las principales remodelaciones parecen haberse vinculado con la transformación y aumento en la escala del ceremonialismo, a partir de la habilitación de un espacio para congregación o escenificación de situaciones. Es probable que la plaza central del sector IV operara en momentos preincaicos, pero cubriendo una superficie mucho menor debido a la presencia de grandes bloques de derrubio. La mano incaica amplió considerablemente el escenario con el simple procedimiento de despedrar el terreno. Pero, en la misma operación, institucionalizó los puntos de interés en el espacio $\mathrm{y}$, a través de muros y aberturas, lo delimitó y condicionó su acceso. Las obras sólo adquirieron utilidad en el plano de lo simbólico, en relación tanto con los ritos de agua y las prácticas agrícolas como con la integración del asentamiento a la organización estatal.

La gran roca rodeada por plataformas que preside la plaza del sector IV presenta las características de un ushnu, con modalidades conocidas en otras instalaciones del territorio del Tawantinsuyu (Bingham 1922:246-248; Deaborn et al. 1998; Hyslop 1990:69-83; Meddens 1997). Es probable que el peñasco, orientado hacia las cumbres nevadas, constituyera, en épocas previas, una huaca de alcance local vinculada con el culto al complejo ancestros-montañas-fertilidad de la naturaleza. Se han señalado situaciones arqueológicas similares en el valle de Yocavil. En los sectores I y XIII de Rincón Chico, algunas monumentales rocas derrumbadas de la ladera del cerro y acumuladas a su pie, fueron incorporadas al paisaje cultural rodeándolos de plataformas pircadas $\mathrm{y}$, en algunos casos, ejecutando labrados sobre ellos. Las excavaciones realizadas en algunas de estas estructuras permitieron recuperar evidencias de sacrificios de animales y, probablemente, de humanos, así como de la realización de ceremonias en las cuales participaron reconocidos elementos rituales de la región como las campanas ovales (González y Cabanillas 2004; González y Doro 2004). De igual modo, se conoce documentación etnohistórica producida a principios del siglo XVII en la cual sacerdotes jesuitas informaron sobre "mochaderos" o lugares de culto indígenas conformados en torno a grandes piedras que eran adornadas con plumas y esculturas de madera (González 1983; Márquez Miranda 1946:261-262).

Los administradores cuzqueños habrían aprovechado el carácter sagrado del peñasco, redimen- 
sionándolo y, sin que perdiera relación con las divinidades tutelares de la región, en especial en lo referente a la distribución de las aguas, le habrían otorgado una mayor significación política, sustrayendo del control local su potencial simbólico e incorporándolo a la estructura religiosa estatal (Brown 1998:23; Farrington 1998:55; Pease 1972:51 52; Rowe 1982:108; Wachtel 1973:159). Esta estrategia conllevó amplificar la monumentalidad del peñasco, mediante la construcción de una estructura de base, con tendencia piramidal y planificada, de forma tal, que permitiera su explotación escenográfica. De tal forma, se dispuso una rampa o escalera de acceso en el lado noroeste, el opuesto al espacio de la plaza, y que conducía a los oficiantes a la cima plana del peñasco. La importancia que se le adjudicó a estas obras quedó manifestada en el trabajo invertido, con la selección y preparación de cientos de bloques de piedra y su cuidadosa disposición, evidenciando una técnica constructiva muy diferente a la que se observa en el resto de las construcciones.

Puede ser pertinente para valorar el alto potencial simbólico que, desde siglos antes, acreditaba la zona a nivel regional, recordar que en la inmediata cercanía del asentamiento se encuentran las conocidas rocas grabadas de Campo del Ingenio y Mesada Barrera (Berenguer y Martínez 1986; Lorandi 1966). Un fechado radiocarbónico obtenido en la excavación de una estructura de estos sitios arrojó un valor correspondiente a 670 \pm 85 a.p. (Cigliano 1966; Cal. 1 sigma. 1.2801.399 d.C.; Cal. 2 sigmas 1.221-1.431 d.C., IVIC177). Como adelantáramos, en el sector II de Ampajango 2, correspondiente al desarrollo exclusivamente local, fue registrada una roca grabada de similares características a las de aquellos sitios. Ello sugiere la posibilidad que en el asentamiento hubieran convivido las prácticas del culto tradicional con las oficializadas por el estado, teniendo en cuenta la conducta tolerante que el incario mostró en ese aspecto (Conrad 1992; Patterson 1992).

Otro conjunto de estructuras en donde las técnicas constructivas incaicas fueron aplicadas con mayor dedicación fue en Ampajango 3, Casas Viejas, y el hecho no parece casual. Tal como fuera señalado, estas estructuras, a modo de kancha y con paredes de piedras seleccionadas, se levantaron a unos $100 \mathrm{~m}$ del sector IV, a una cota más elevada y en un espacio que no fue previamente ocupado. En este caso, adjudicamos al conjunto una funcionalidad eminentemente política. Por su posición, interpretamos que su mayor utilidad práctica fue la de actuar, a modo de panóptico, como estación de control, efectivo y simbólico, de los acontecimientos que tenían lugar en el área de la plaza central. Al mismo tiempo, las estructuras eran perfectamente visibles desde Ampajango 2 (lo son en la actualidad, a pesar de los derrumbes) y presumiblemente representaron para los pobladores la omnipresencia del poder. De alguna manera, la distribución espacial, en los ejes horizontal y vertical, resultaba una metáfora de las relaciones sociales imperantes. La separación y la oposición alto/bajo, pueden verse como marcadores de espacios que tanto resultaban potencialmente peligrosos para los no autorizados (Theoratus y La Pena 1994:22) como también poniendo de relieve la diferenciación entre las elites dominantes y los comunes (Moore 1996). El ámbito de conjunción que proporcionaba la plaza central con su elaborado ush$n u$ era, al mismo tiempo, un ámbito de oposición: por un lado, el mundo de los dioses y sus representantes, los funcionarios estatales; por otro, el reino de lo cotidiano y la gente del común. El ceremonialismo que se desarrollaba en el lugar, encauzado como actividades comunitarias dirigidas hacia las divinidades, entrañaba un reconocimiento de la autoridad de los oficiantes y legitimaba la estructura de poder. No obstante, no pueden dejarse de lado probables funciones militares, en particular en el caso de Ampajango 7, Loma Redonda, caracterizada por las murallas perimetrales que remarcan el amplio contorno de su cima. Se trata de un clásico reducto de cumbre apropiado para el refugio y la defensa en situaciones de conflictos. Al respecto, cabe recordar que en 1659, durante las campañas españolas para dominar a las sociedades indígenas del valle, Ampajango fue escenario de una furiosa batalla entre ambos bandos (Lorandi y Boixadós 1988:358).

Considerando el espacio regional, Ampajango 2 parece haber formado parte de un entramado de instalaciones imperiales que sugiere un particular interés por el control de la zona. Dicho control, más allá de responder a fines concretos y materiales, se ejerció no sólo a través de componentes infraestructurales, sino tomando en cuenta meta-mensajes derivados de la imposición de tales componentes en el paisaje. En el confín del valle y a unos $10 \mathrm{~km}$ al sudoeste de Ampajango 2, se le- 
vantaba el tambo de Punta de Balasto, sobre el camino troncal que recorría el fondo del bolsón y en un punto del paisaje sin ocupaciones previas. El tambo fue interpretado como una estación de control del tránsito de personas y del voluminoso tráfico de bienes dentro del conjunto de instalaciones administrativas del sur del Collasuyu (González 1999:227-228). Por ejemplo, una carta del jesuita Juan de León menciona que cada año pasaban por el valle "quatro cientos carneros cargados de oro" como parte de la renta para el Inca ${ }^{2}$. En el tambo, además del camino troncal señalado, confluían tres importantes ramales. Uno de ellos, con rumbo sudoeste, conectaba con los conspicuos centros de Hualfín y Shincal (Raffino et al. 1985). Otro, hacia el sur, tras una estación en el tambo de Ingenio del Arenal, enlazaba con los distritos mineros de Capillitas Atajo y Andalgalá (González 1982:333). El tercero ascendía hacia el sudeste, por la quebrada del río Pajanguillo hasta llegar al establecimiento de Nevados del Aconquija, con las estaciones intermedias de Pajanguillo, Becobel y Tambo Colorado. Pero, además de las consideraciones funcionales, la instalación del tambo en un punto del paisaje previamente no ocupado pudo contener un fuerte contenido simbólico, materializando la apropiación del espacio regional y su reorganización en torno a los principios del orden estatal (González y Tarragó 2005).

Asociado a Punta de Balasto se encuentra Bicho Muerto (González 1995), representando la ocupación parcial de una población preexistente. Es posible que en el primer momento de la expansión incaica Bicho Muerto hubiera actuado como una fortaleza interna (González 1980), función que más tarde, con la ocupación consolidada, hubiera sido más simbólica que efectiva. Se dispone de información etnohistórica que indica que el Morro Blanco, a cuyo pie se levanta el asentamiento, constituía una venerada huaca en tiempos prehispánicos tardíos (Piossek Prebisch 1984). Su potencial simbólico habría estado incrementado por los depósitos minerales que albergaba la formación (Salazar Soler 1997) y que abastecían a los cercanos establecimientos metalúrgicos de El Trapiche y Fundición Navarro (González 1997). Es posible, entonces, que algún sector de Bicho Muerto constituyera un "mochadero minero", en una situación similar a las registradas en otros lugares sur andinos, como en Kona Kona, en la subregión del alto Loa (Castro 1992).

\section{Palabras Finales}

Los datos generados hasta el momento en los trabajos llevados a cabo en Ampajango 2 son insuficientes como para elaborar conclusiones definitivas y detalladas acerca de la historia del asentamiento, la variabilidad intrasitio y sus relaciones con otras instalaciones locales e imperiales del área. No obstante, nos permiten proponer algunas hipótesis como las adelantadas y que irán siendo fortalecidas o rechazadas a medida que avancen los trabajos de investigación.

Uno de los aspectos que nos parecen relevantes para subrayar se refiere a la variabilidad en el registro arquitectónico como resultado de la presencia incaica. Ello se manifestó en distintos niveles; influyendo tanto en la construcción del espacio dentro del sitio como en la organización del paisaje en el área bajo estudio. Ampajango 2, Rosendo Cáceres, nos muestra técnicas constructivas incaicas limitadas a sectores seleccionados del asentamiento, manteniendo la estructura arquitectónica previa del sitio de génesis local. El proceso de selección de los sectores, tanto aquellos de índole pública como productiva (agrícola y artesanal), no se basó únicamente en cuestiones prácticas sino que también tuvo en cuenta los contenidos simbólicos derivados de la circunscripción de determinados espacios. Las modalidades arquitectónicas locales, tanto en el tratamiento de los materiales como en su disposición, aparecen combinadas con las reconocidas pautas imperiales.

En este sentido, uno de nuestros propósitos al presentar el caso de Ampajango 2 fue poner de relieve que la ocupación incaica en el sur del valle de Yocavil y, probablemente, en otras áreas del Collasuyu, no parece haberse basado únicamente en rígidas decisiones del gobierno central, sino que factores residentes en las cualidades organizativas de las sociedades dominadas pudieron jugar importantes roles que matizaron el modo efectivo que asumió la ocupación. En consecuencia, el registro arqueológico adquiere una variabilidad que exige superar las tipologías de rasgos ordenados jerárquicamente, utilizadas para evaluar el grado de presencia imperial. Esto no significa negar la importancia de estos indicadores. Lo que pretendemos señalar es que la pobreza o la ausencia de tales rasgos no implican, necesariamente, que el estado haya desdeñado determinadas localizaciones. En conexión con esto, tan importantes como las obras de infraestructura, 
las estrategias de dominación incluyeron la transformación imperial de los sistemas simbólicos, entre los cuales la concepción del espacio figuró entre los más trascendentes.

Agradecimientos: Nuestro reconocimiento para los miembros del equipo que participaron en las investigaciones desarrolladas en el sur del valle de Yocavil, en particular a Gerónimo Pratolongo, Valeria Palamarczuk, la Prof. Susana F. Renard de Coquet, Javier Mozo, Mariela Tancredi, Mariano Manaziewicz, Paula Campo y Ana Vargas. También queremos reconocer el apoyo constante que nos brindó la historiadora Sandra Patricia Sánchez en la utilización de documentos escritos y en la realización de los trabajos de campo.

\section{Referencias Citadas}

Berenguer, J. y J. L. Martínez

1986 El río Loa, el arte rupestre de Taira y el mito de Yakana. Boletín del Museo Chileno de Arte Precolombino 1:79-99.

Bingham, $\mathrm{H}$.

1922 Inca Land. Explorations in the highlands of Peru. Houghton Mifflin Co., Boston.

Brown, D.

1998 Water and power in the provinces: Water management in inka centers of the Central Highlands of Peru. Tawantinsuyu 5:23-36.

Castro, V.

1992 Nuevos registros de la presencia Inka en la provincia de El Loa, Chile. Gaceta Arqueológica Andina 21:139-154

Cigliano, E. M.

1966 Contribución a los fechados radiocarbónicos argentinos (I). Revista del Museo de La Plata, NS, VI, Antropología 29:1-16.

Conrad, G.

1992 Inca imperialism: The great simplification and the accident of the empire. En Ideology and Pre-Columbian Civilizations, editado por A. Demarest y G. Conrad, pp. 159174. School of American Research Press, Santa Fe.

Cosgrove, D.

1980 Social Formation and Symbolic Landscape. Croom Helm, London.

Criado Boado, F.

1993 Límites y posibilidades de la arqueología del paisaje. Revista del Instituto de Antropología de la Universidad de Sevilla 2:9-55.

Deaborn, D., M. Seddon y B. Bauer

1998 The sanctuary of Titicaca: Where the sun returns to earth. Latin American Antiquity 9, 3:240-258.

Farrington, I.

1998 The concept of Cusco. Tawantinsuyu 5:53-59.

González, A. R.

1980 Patrones de asentamiento incaicos en una provincia marginal del imperio. Implicaciones socioculturales. $R e$ laciones de la Sociedad Argentina de Antropología, NS, XIV, 1:63-82.

1982 Las "provincias" incas del antiguo Tucumán. Revista del Museo Nacional XLVI:317-380.

1983 Nota sobre religión y culto en el Noroeste argentino prehispánico. Baessler Archiv. Neue Folge XXXI:219-282, Berlín.

González, L. R.

1995 Blues del Bicho Muerto. Observaciones arqueológicas en el sur del valle de Yocavil. Palimpsesto. Revista de Arqueología 4:97-102.
1997 Arqueología y etnohistoria: evidencias de actividades minero metalúrgicas coloniales en el sur del valle de Santa María (Pcia. de Catamarca). En Actas XIV Congreso Nacional de Arqueología Chilena, editado por M. Cervellino Giannoni, v.1: 29 - 47. Copiapó.

1999 Tambo feroz. Nuevos datos sobre el asentamiento de Punta de Balasto y la ocupación incaica en el sur del valle de Santa María (Pcia. de Catamarca). En Actas XII Congreso Nacional de Arqueología Argentina Vol.1:222-232.

González, L. R. y E. Cabanillas

2004 Las campanas ovales de bronce del Noroeste argentino prehispánico. Revista Andina 38:225-251.

González, L. R. y R. Doro

2004 Jardines de piedras. Estructuras ceremoniales en Rincón Chico. Etnia 46-47:147-168.

González, L. R. y T. Palacios

1996 El volar es para los pájaros. Análisis técnicos de dos piezas metálicas procedentes del valle de Santa María, Pcia. de Catamarca. Arqueología 6:25-46.

González, L. R. y M. N. Tarragó

2004 Dominación, resistencia y tecnología: La ocupación incaica en el noroeste argentino. Chungara Revista de Antropología Chilena 36:393-406.

2005 Vientos del sur. El valle de Yocavil (Noroeste argentino) bajo la dominación incaica. Estudios Atacameños 29:67-96.

González Godoy, C.

1996 El criterio monumentalista y su aplicación en la arquitectura Inka de Chile central. Boletín Sociedad Chilena de Arqueología 23:33-37.

Hyslop, J.

1990 Inka Settlement Planning. University of Texas Press, Austin.

Hyslop, J. y J. Schobinger

1991 Las ruinas incaicas de los Nevados del Aconquija (prov. de Tucumán, Argentina). Informe preliminar. En El Imperio Inka: Actualización y Perspectivas por Registros Arqueológicos y Etnohistóricos, Comechingonia 2, Córdoba.

Lorandi, A. M.

1966 El arte rupestre del Noroeste argentino. Dédalo 11(4):15-172.

Lorandi, A. M. y R. Boixadós

1988 Etnohistoria de los valles Calchaquíes en los siglos XVI y XVII. Runa 17-18:263-419.

Márquez Miranda, F.

1946 Los Diaguitas. Inventario patrimonial arqueológico y 
paleoetnográfico. Revista del Museo de La Plata, NS III:5-300.

Meddens, F.

1997 Function and meaning of the usnu in Late Horizon Peru. Tawantinsuyu 3:4-21.

Meyers, A.

1999 Reflexiones acerca de la periodización de la cultura Inka: perspectivas desde Samaipata, oriente de Bolivia. En Actas XII Congreso Nacional de Arqueología Argentina Tomo I: 239-251.

Moore, J.

1996 Architecture and Power in the Ancient Andes. Cambridge University Press. Cambridge.

Morris, C.

1988 Progress and prospect in the archaeology of the Inca. En Peruvian Prehistory, editado por R. Keatinge, pp. 233256. Cambridge University Press, Cambridge.

Nastri, J.

1998 Patrones de asentamiento prehispánicos tardíos en el sudoeste del valle de Santa María (Noroeste argentino). Relaciones de la Sociedad Argentina de Antropología 22/23:247-270.

Patterson, T.

1992 The Inca Empire. Berg, Oxford.

Pease, F.

1972 Los Últimos Incas del Cuzco. Lima.

Penning Roswell, E.

1986 Themes, speculations and an agenda for landscape research. En Landscape, Meanings and Values, editado por C. Penning Roswell y D. Lowenthal, pp. 114-128. Allen y Unwin, London.

Piossek Prebisch, T.

1984 Relación Histórica de Calchaquí. Escrita por el Misionero Jesuita Padre Hernando de Torreblanca en 1696. Ediciones Culturales Argentinas, Buenos Aires.

Raffino, R.

1981 Los Inkas del Collasuyu. Ramos, La Plata.

1988 Poblaciones Indígenas de la Argentina. Tipográfica Editora Argentina, Buenos Aires.

Raffino, R., R. Alvis, L. Baldini, D. Olivera y M. Raviña 1985 Hualfín El Shincal Watungasta. Tres casos de urbanización Inka en el N. O. Argentino. Cuadernos del Instituto Nacional de Antropología 10:425-455.

Reynoso, A.

2003 Saber del Sol su Frontera. Arqueoastronomía en el Poblado de Rincón Chico, Provincia de Catamarca (9001600 d.C.). Tesis de Licenciatura, Facultad de Filosofía y Letras, Universidad de Buenos Aires.
Rowe, J.

1982 Inca policies and institutions relating to the cultural unification of the empire. En The Inca and Aztec States. 1400 1800. Anthropology and History, editado por G. Co1lier, R. Rosaldo y J. Wirth, pp. 93-118. Academic Press, New York.

Salazar Soler, C.

1997 Las huacas y el conocimiento científico en el siglo XVI: a propósito del descubrimiento de las minas de Potosí. En Saberes y Memorias en los Andes, editado por T. Bouysse Cassagne, pp. 237-257. CREDAL IFEA, Lima.

Tarragó, M. N.

1964 Estado actual de la investigación arqueológica en el Valle de Santa María, provincias de Catamarca, Tucumán y Salta. Manuscrito en posesión del autor.

Tarragó, M. N.

1987 Sociedad y sistema de asentamiento en Yocavil. Cuadernos del Instituto Nacional de Antropología 12:179-196. 1998 El patrimonio del valle de Santa María en peligro. En 50 años de aportes al desarrollo y consolidación de la antropología argentina. Homenaje a Alberto Rex González, pp. 205-253. Facultad de Filosofía y Letras Fundación Argentina de Antropología, Buenos Aires.

1999 Las sociedades del sureste andino. En Historia General de América Latina, T. 1, Las Sociedades Originarias, pp. 465-480. UNESCO, París.

Tarragó, M. N. y J. Nastri

1999 Dimensiones de la complejidad santamariana. En $A c$ tas XII Congreso Nacional de Arqueología Argentina, Vol. II, pp. 259-264, La Plata.

Tarragó, M. N. y L. R. González

2004 Ceremonialismo y arquitectura social en Yocavil, Catamarca. Manuscrito en poder de los autores.

Theoratus, D y F. Lapena

1994 Wintu sacred geography of Northern California. En Sacred Sites, Sacred Places, editado por D. Carmichael, J. Hubert, B. Reeves y A. Schanche, pp. 20-31. Routledge, London.

Tilley, C.

1994 A Phenomenology of Landscape. Places, Paths and Monuments. Completar Oxford.

Wachtel, N.

1973 Sociedad e Ideología. Ensayos de Historia y Antropología Andinas. Instituto de Estudios Peruanos, Lima.

Williams, V.

1994 Jerarquización y funcionalidad de centros estatales incaicos en el área valliserrana central del NOA. Shincal 4:11-34.

Williams, V. y T. D'Altroy

1998 El sur del Tawantinsuyu: un dominio selectivamente intensivo. Tawantinsuyu 5:170-178.

\section{Notas}

1 Una versión preliminar de este trabajo fue presentada en el XV Congreso Nacional de Arqueología Chilena (Arica 2000), con el título "La Ventana Indiscreta: Variabilidad en los modos arquitectónicos incaicos. Un caso de estudio en el valle de Yocavil" con la participación, además de los autores, de Mariela Tancredi, Mariano Manaziewicz, Paula Campo y Ana Vargas.

2 León, Juan de. Carta al Capitán Hernández de Pedroza, 24 de junio de 1657. 
